\title{
Promoting Functional Communication Within the Home
}

\author{
Andy Bondy ${ }^{1}$ (D) $\cdot$ Catherine Horton ${ }^{1} \cdot$ Lori Frost $^{1}$
}

Published online: 12 May 2020

(C) Association for Behavior Analysis International 2020

\begin{abstract}
Functional communication skills are essential for all learners and must be promoted within all environments, including the home. During this time of home confinement, many families will need to look at opportunities for their children to use existing functional communication skills or even to acquire new skills. This article describes a set of 9 critical communication skills and provides a variety of examples of how families can improve the use of these important skills. Some of these involve speaker (expressive) skills, whereas others involve listener (receptive) skills.
\end{abstract}

Keywords Functional communication $\cdot$ Families $\cdot$ Home-based teaching

During this time of uncertainty and with our learners at home for extended periods of time, effective communication is essential. Children must be able to clearly communicate with their caregivers. Caregivers must structure opportunities to ensure continued growth and development of functional communication skills. Professionals are increasingly required to teach in new and often remote contexts. It has never been more important for behavior analysts to be clear in their guidance and skill instruction to caregivers. As the Behavior Analyst Certification Board's (BACB's) Professional and Ethical Compliance Code for Behavior Analysts notes in Code 1.05(b) "When behavior analysts provide behavior analytic services, they use language that is fully understandable to the recipient of those services while remaining conceptually systematic with the profession of behavior analysis" (BACB, 2014). In this article, nine critical communication skills will be presented. In addition, common scenarios are described with

$\overline{\text { Editor's Note This manuscript is being published on a highly expedited }}$ basis, as part of a series of emergency publications designed to help practitioners of applied behavior analysis take immediate action to adjust to and mitigate the COVID-19 crisis. This article was submitted on April 4, 2020, and received final acceptance on April 7, 2020. The journal would like to especially thank Dr. Cynthia Anderson for her expeditious review of the manuscript. The views and strategies suggested by the articles in this series do not represent the positions of the Association for Behavior Analysis International or Springer Nature.

Andy Bondy

abondy@pecs.com

1 Pyramid Educational Consultants, Inc., New Castle, DE, USA general guidelines and considerations for teaching effective replacements. Note that both the scenarios and solutions are intentionally lacking behavior-analytic jargon. All of the recommendations are based on published research, but citations and technical language have been intentionally left out. Rather, the focus is on clear, concise recommendations that are conceptually consistent with the science of behavior analysis. Readers are encouraged to either share the article in the entirety with caregivers or use the examples that may be most relevant to new skill development. We are intentionally using a language style that does not need further translation in order for it to be helpful to parents and other nonprofessionals.

\section{Prioritizing and Assessing Critical Communication Skills}

\section{Overview of Nine Critical Communication Skills}

To ensure success in the home environment, functional communication skills are essential. Functional communication is defined as a behavior that is directed to another person who in turn provides either direct or social rewards. Nine critical communication skills will be described. These skills are critical because, if children cannot calmly and effectively engage in each skill, then they will most likely try other means to obtain the same outcome. Typically, these other means are challenging - crying, fussing, shouting, hitting, and so on. We have identified nine such skills, of which some are skills to be used as a speaker and some are to be used as a listener, as outlined in Table 1. 


\section{Assessing Critical Communication Skills}

It is helpful to assess each of these critical skills for each learner. It is important to complete a checklist involving these skills in addition to other measures used to assess a child's language skills. That is, knowing that a child has a language age equivalent of a 9-year-old will not necessarily indicate whether the child can accomplish each skill independently. See the Appendix Table 2 for a suggested template to assess these critical communication skills.

For each skill, it will be helpful to think about how a child currently handles a particular situation. For example, when a child sees a toy or something else he or she wants, what does the child do? Is his or her response appropriate or problematic? If a 2-year-old pointed to a book on a shelf that the child wanted to look at, that might be considered appropriate for that skill and age level. On the other hand, if the child stood and stomped his or her feet and screamed until someone gave him or her the book, that would be something you would want to work on.

After completing the form regarding all nine skills, rate each of the problem areas and note how difficult each problem is. That is, prioritize the severity of the problems to help determine which ones will be worked on first. For example, if a child requests help by handing a parent items that do not work, but the aim is to have the child say the word "help," that would not be as important as working on screaming when the child cannot get toys that are out of reach.

Given the current mandates for social distancing, behavior analysts are urged to guide caregivers through the completion of the checklist using a telehealth model. Through interviews with the caregivers, the behavior analyst can guide the discussion to help determine if the learner's current communicative repertoire is effective. Behavior analysts should also lead the analysis to determine priorities to help achieve two goals. One goal helps develop crucial communication skills in anticipation of problems and stresses that may arise in a child's life in the near future. The other goal helps to ensure that specific critical communication skills will serve as functionally equivalent alternative behaviors to any identified challenging behavior in the home setting.
Tips for Teaching Critical Communication Skills: Problems and Potential Solutions

To begin, review routines and activities that are problematic for the child and be sure to consider what role expressive or receptive communication plays in the problem. For children with autism spectrum disorder (ASD), a paucity or lack of appropriate communication skills is often among the biggest impediments to smooth family functioning. When a child is having difficulties with a family activity or routine, determine whether a problem with one or more of these specific communication skills is contributing to the difficulty.

After completing the critical communication skills checklist to pinpoint what areas of communication are posing the biggest problem for the child and family, the next step is to figure out what the child can learn to do instead of what he or she is doing now. The following sections give many examples of potential problems with communication that children with ASD have, together with some potential solutions. Once an alternative skill is identified, add it to the list of teaching goals. As these skills are acquired, review the prioritization of all nine communication skills to help determine which new skills should be addressed.

\section{Requesting Reinforcers}

Asking for a desired item is an essential and fundamental communication skill. Requesting (i.e., manding in applied behavior analysis jargon) allows people to get access to items and activities that are essential for day-to-day living or promotes enjoyment and greater interactions with others. It is important to begin teaching requesting by having children ask for items that are highly preferred or needed to complete an important task or routine. Prior to starting these lessons, identify several people, places, and/or things that are important from the child's perspective. There are many resources to help conduct preference assessments in and around the home.

It also is recommended to distinguish what a child likes or prefers from what a child needs when assessing motivating items and activities. For example, Mary enjoys eating vanilla pudding but does so only with a spoon, never with her fingers. It is fair to say that she likes pudding, but it would be unusual
Table 1 Nine Skills of Speaker and Listener Behavior

\begin{tabular}{ll}
\hline Speaker Skills & Listener Skills \\
\hline Asking for reinforcers & Responding to having to wait; tolerating no \\
Requesting help/assistance & Transitioning (going from one activity to another) \\
Asking for a break & Following directions (spoken and/or visual instructions) \\
Accepting ("Yes!") & Following a schedule \\
Rejecting (“No!") & \\
\hline
\end{tabular}


to declare that she likes spoons. Mary does not have a collection of spoons, and when asked to name things she likes or enjoys, she never mentions spoons. Therefore, parents are advised to list both things their children like and things they may need within a context. Furthermore, many traditional approaches to preference assessment attempt to compare individually offered items for the purpose of ranking them within a hierarchy. Although it may be true that a child prefers a ball in comparison to a napkin, this strategy places too much emphasis on individually presented rewards as opposed to combinations. Simply put, imagine how most children would respond if asked, "Do you want peanut butter or jelly?" Adults rarely simply order coffee from a barista. Therefore, parents are advised to investigate combinations of items or activities in order to enhance their effectiveness: cookies and milk, french fries and ketchup, music and dancing, and so on.

- Problem: Three-year-old Derek wants to play his favorite game, but his father has put the iPad on the top shelf above the television where Derek cannot reach it. He tries to climb on top of the television but cannot quite make it. He begins whimpering and jumping up and down. When his mother comes into the room, not knowing that Derek's father put the iPad out of reach, she cannot figure out what he wants.

- Potential solution: Teach Derek to exchange a picture to ask for the iPad.

- Problem: Eight-year-old Sam wants some juice, and the juice carton is empty. He goes to his mother and says, "Sam, say you want some juice."

- Potential solution: Re-create the situation by giving Sam just a little juice, and as he finishes it, guide him to say, "I want some juice."

- Problem: Fourteen-year-old Darlene is about to do some homework. She looks at her sister who is on the computer and screams, "Get off now!"

- Potential solution: Do not try to teach a new skill while Darlene is screaming. Re-create the situation with her sister, and as Darlene approaches her, prompt her to say, "I have homework to do. Can I use the computer soon?"

The key to teaching this type of lesson is to create situations involving the use of moderately rewarding items or activities when the child is relatively calm. Use these types of items at first to minimize the potential for an emotional reaction to not getting the most powerful potential reward. In the midst of a tantrum or meltdown, it is very difficult to teach a new skill. Instead, re-create the situation and be prepared to prompt or guide the new or replacement skill at the right time and context. Teach the new form of communicating the request without requiring a big change in performance - a single picture before a series of pictures, a single spoken word before a full sentence, and so on.

\section{Requesting Assistance}

Asking for help is universally important because everyone at some time will be in a situation where the solution to a problem must come from someone else.

- Problem: Joey is playing with his favorite electric train set. He has learned to set the track up on his own; connect the train engine, cars, and caboose; and put the train on the track and start the train. Today when the train rounds the first corner, it falls off the track. Joey tries several times to restart the train but does not notice that the track is not properly connected at the first corner. After several attempts to get the train going, each time ending with a derailed train, Joey screams and throws the train across the room.

- Potential solution: Re-create the situation by intentionally misaligning part of the track. Before Joey gets upset, teach him to bring the train to his sister and gesture for help. Over time, create other more challenging problems for Joey to encounter.

- Problem: Amanda is working on her math homework at the kitchen table along with her brother. She carefully adds the numbers for each problem, reciting the problem aloud as she works. ("Seven plus eight equals fifteen.") When her pencil lead breaks, she grabs her brother's pencil.

- Potential solution: Re-create the situation by giving Amanda a pencil with a broken nib and teach Amanda to point to her brother's pencil and say, "Can I use that for now?"

In teaching a child to request help, identify many activities and times during the day when it is natural for the child to ask for help. The following are a variety of ideas to capture and create opportunities to request assistance:

- blow bubbles

- blow up a balloon

- put coins in a vending machine

- cut food

- cut paper

- open curtains

- open doors

- open a bottle 
- open food packets

- open a milk or juice carton

- pour from a pitcher or carton

- put on shoes and socks

- take a cap off a marker

- tie shoelaces

- turn the lights on/off

- reach for a towel to dry hands

- turn the music/television on/off

- zip or unzip a coat

- wind up a toy

- enter a tablet passcode

- charge a tablet

The key to teaching this skill is to set up help situations that are easy to solve at first and then to gradually make the situation more challenging. If the situation rapidly leads to challenging behaviors, then re-create the problem at a less intense level. For example, once Joey has calmly handled the singletrack problem, we should not immediately add 10 broken tracks and hope for the best; instead, we should gradually introduce new problems to solve. We are the ones creating the "problem" so we can modulate the severity from opportunity to opportunity.

\section{Requesting a Break}

Everyone has been in situations where the demand is too high or fatigue has set in due to the length of the task at hand. In these cases, asking for a break is appropriate to gain some time to recuperate. Requesting a break effectively leads to avoiding or escaping from certain events in a socially acceptable manner. Although parents may be able to "read" when their children need a break, children also need a calm way to ask for a break on their own. As with learning to ask for help, the key will be for the child to ask for a break before having a tantrum.

- Problem: Maria has started distance learning and is listening to her teacher sing a song. Shortly after the singing begins, Maria brings her hands to her ears, starts to scream, and backs away from the computer.

- Potential solution: Teach Maria to use a break card when she is overwhelmed by a situation. In the future, Maria can hand her father a card that says "Break" and walk to a neutral break area.

- Problem: Reggie's math assignment includes 50 longdivision problems. Reggie is generally accurate with his math equations and can work for up to 15 min independently. After 15 min pass, Reggie breaks his pencil, throws it across the room, and yells, "I hate math!"
- Potential solution: Teach Reggie to say "I need to chill for a minute" when he has worked for $15 \mathrm{~min}$ but before he screams or breaks his pencil.

When teaching this skill, try to create the opportunity to request a break before the breaking point. Once a tantrum has begun, it is too late to calmly request a break. If a child can handle 10 min of a task but not 15 , try to stretch to 11 or 12 before pushing for the full $15 \mathrm{~min}$ of work.

\section{Rejecting}

Rejecting offers from other people allows participation in interactions with communicative partners who are determining what, specifically, may be wanted in the situation. When someone cannot politely or calmly reject something that is not liked, trouble usually ensues.

- Problem: Jacqui, 19 years old, is having dinner with her parents. She has learned to sit with her family at mealtimes, and virtually all meals at her house involve Mom or Dad handing her a plate of her favorite foods. Tonight, Jacqui's mother tries to pass Jacqui the bowl of broccoli. Jacqui will not take it from her, and when her mother tries to spoon some broccoli onto Jacqui's plate, Jacqui forcefully pushes the bowl away, knocking over her water glass.

- Potential solution: Teach Jacqui to shake her head no when she is offered foods she does not like.

- Problem: Jamie wants to watch a movie. Her sister tries to help and puts on the Frozen video because it is one of Jamie's favorite movies. Jamie screams, "Thomas! Thomas! Thomas!"

- Potential solution: Jamie learns to say "No, thanks" and give her sister a picture of the video she wants to watch.

For this lesson to be successful, the rejection must work. That is, if a child communicates no to the offered item, that item must be removed. As with the other lessons, the first lessons should involve items that are mildly or moderately unwelcomed and should not involve items that are deeply feared. For example, use broccoli with Jacqui because it is something she mildly dislikes, as opposed to bananas, the mere smell of which makes her gag and throw up. Present a small amount of the item or activity to be rejected before gradually increasing how much of the item or activity is offered. 


\section{Accepting}

We all can remember times when we have played 20 Questions with a child in order to figure out what was wanted. When holding out a preferred item and asking, "Do you want this?" most often children will simply take it. However, many items cannot be held or even shown, such as when asking, "Do you want to go to the swimming pool?" so children need to indicate "yes!"

- Problem: Eight-year-old Sierra is in the kitchen with her older brother, Sam. Sam is trying to help his sister get a snack and is pulling one food after another out of the snack cupboard, asking, "Is this what you want?" He thinks it is the blue corn chips she wants, but he has not been able to reach them yet. So, without showing them to her, he asks, "Do you want the blue corn chips?" Sierra does not answer. Finally, he reaches them in the back of the cupboard, and when he holds them out to Sierra, she takes them from him.

- Potential solution: When Sam asks, "Is this what you want?" Sierra nods her head.

- Problem: Fourteen-year-old Alexis is helping her mother make cookies. When it is time to stir the dough, her mother asks, "Do you want the big spoon?" Alexis answers, "Big spoon."

- Potential solution: When asked whether she wants something, Alexis learns to say, "Yes!"

It is important to distinguish answering a question from repeating part of the question, as Alexis did in the previous big-spoon example. It is suggested that teaching no versus yes should involve separate opportunities before trying to alternate between the two. Furthermore, answering "Do you want . . . ?" questions leads to very different outcomes than when asking, "Is this a ... ?" questions. When a ball is held up while asking, "Do you want the ball?" a yes results in receipt of the ball. When a ball is held up while asking, "Is this a ball?" a yes merely results in praise, and not the ball itself.

\section{Responding to "Wait" or "No"}

When we say "wait" to a child, the full message is actually complex: "I know what you want, and you are going to get it, but only after some more time passes." Being told to wait is not the same as being told no because in the wait situation, the item or activity will eventually occur. Learning to wait is a crucial skill for everyone and requires providing more details on several issues.
There are three key elements to teaching someone to wait: First, there must be full control over access to whatever it is the child is waiting for. Essentially, saying wait is equivalent to a promise that must be fulfilled if we expect the child to heed the statement the next time it is made. If the provision of the item is not guaranteed, then the lesson will be very difficult to learn. Therefore, start with something that the child wants but that can be given to him or her at any time.

Second, there must be control over how long the child must wait. Start with a time interval that is so short- 1 or $2 \mathrm{~s}$ - that it virtually guarantees that there will be no failure. Then, begin to gradually increase the time interval over a series of opportunities. If too much time is added and there is a problem, simply readjust the next interval to something shorter. Highlight that it is time to practice waiting with a visual cue, such as a large, brightly colored card that has "wait" written on it.

Third, as the wait intervals become 1 min or longer, help the child select something easy to do while waiting. The point is, do not expect someone to simply wait while doing nothing - that remains very hard for all of us. Instead, pick some easy activities such as looking at a picture book or listening to music (as long as the child is not waiting to listen to music).

Here are some more common situations that all families face and their suggested solutions:

- Problem: Mark's mother is on the telephone trying to schedule an appointment. Mark comes up to her and begins tugging on her, trying to get her to move with him. She resists and whispers to Mark, "Just a minute. I'm almost done." Mark falls to the floor and begins screaming.

- Potential solution: Mark's mother teaches him to use a "wait" card. For example, Mom hands Mark a card that says, "Wait," and Mark calmly stands next to her for 1 min. Mom then pays attention to Mark. (Note that if Mark cannot yet read, he can learn to associate this visually unique card with waiting.)

- Problem: Sue's family is planning on having food from her favorite restaurant delivered for dinner. During the early afternoon, Sue begins asking her parents when the food will arrive, and they answer, "Not for several hours," "Later," or "At 6:00." Sue does not know how to tell time and continues to ask every 15 or $20 \mathrm{~min}$, which begins to annoy her parents. By the time the food finally arrives, everyone is frustrated.

- Potential solution: Her parents place a picture of the restaurant on Sue's picture schedule, which she quietly checks several times during the afternoon. 
- Problem: Marshall has finished his homework and a bowl of ice cream that he had earned. He asks his father if he can have another bowl of ice cream. His father says, "No, one is enough." Marshall ignores his father and heads for the freezer for more ice cream. His father blocks his path, and they start to yell and shout at each other.

- Potential solution: Marshall's parents teach him "the no game." They tell Marshall that sometimes they will say no to him, but if he responds calmly, they will provide other types of rewards - special time with them when he can pick which game to play. They give Marshall an index card with five open circles and tell him that he will earn a token each time he calmly responds when they say no. When all five circles are filled, he can pick a game to play. At first, Marshall's parents arrange to say no at times when it does not seem highly important to Marshall. For instance, he is about to sit on one chair at the dinner table, and they say, "No, please sit on that chair." When he follows through, he earns a token. After several weeks of this type of practice, Marshall asks once again for more ice cream. When his father says no, Marshall calmly walks out of the kitchen, and his father praises him while giving him a token.

No one is perfect, so it is likely that when time is added to this lesson, the next change may lead to a failed opportunity. It is not the learner who has failed; it is the teacher who set too high a level. Therefore, cope with the reaction as best you can, and then reset the opportunity at an interval that is more likely to succeed.

\section{Following Directions}

Responding to directions is viewed as a critical communication skill because of the potential risks associated with failing to understand a message. For example, when Mom shouts to her son, "Don't walk in front of the swings!" failure to respond could result in injury. It is important to first teach children to respond to directions that will produce meaningful and desired outcomes from the children's point of view.

- Problem: Angela's parents report that Angela sometimes looks toward them when they call her name. If she is engaged in a favorite activity, however, she does not respond when they say, "Come here." She seems to follow directions some of the time, but not always. For example, yesterday when her father told her to put her shoes away, she did not do so. But this morning, as he was getting on his coat so they could go to the park, he told Angela to get her shoes, and she ran right to them.
- Potential solution: Angela's parents can teach her to listen for her name paired with "come here" by rewarding her with favorite items (e.g., toys, snacks) for coming over.

Behavior analysts readily distinguish between requests and comments because of the important differences in the outcomes. Asking for a ball yields the ball, whereas saying "that's a ball" leads to praise. This analysis should extend to following directions. "Get the ball" leads to the ball, whereas "point to the ball" leads to praise. It is suggested that directions at home should initially result in a child receiving items and activities in a direct fashion before lessons that only lead to social outcomes are introduced. Just as children must eventually learn to request and comment, so too should children learn to respond to what others are communicating about for both types of outcomes.

\section{Following a Schedule}

Most adults keep track of all the important things needed to be done today, this week, or this month by using some type of written calendar system. That is, whatever our level of vocal communication, most adults rely on a visually mediated system to help them navigate their schedules. Children also need to know what is expected of them and when activities will occur. Therefore, they should be taught how to use systems that contain information about their future schedules of activities.

Schedules can come in many shapes and forms. If a child can read, then using words may be helpful, but children with ASD can learn to use pictures or other three-dimensional items to keep track of their schedules. When pictures are used within a schedule, it is a good idea to first teach what the pictures mean (i.e., what to do when one sees a picture) and only then teach the child how to use the schedule itself. Teach one lesson at a time, and avoid mixing them together. The pictures used should refer to important objects, activities, or areas of the home or neighborhood. The child should respond to the picture without someone telling him or her what the picture means - otherwise, why use the pictures? For example, when shown a picture of a spoon, the child should get the spoon and go to the area or start the activity shown without someone saying, "Right! Get the spoon!"

One strategy involves arranging the pictures in a top-down fashion to show the sequence of events, whereas other strategies involve notebooks that can be used to show a single activity on each page. More complex systems can be developed over time.

- Problem: Mary wants to play a game on her smart tablet right now. Her mother wants Mary to complete her online 
lesson that her school has assigned. Mary throws a tantrum while screaming, "Now! Now!"

- Potential solution: Mary's mother introduces a visual schedule of the important activities of the day. When Mary wants to play her game, her mother puts the picture of the tablet on the schedule after the "school lesson" picture.

- Problem: On weekdays, David's parents maintain a very predictable routine in the household. David seems content to follow along with the family's activities. On weekends, though, when the schedule is more unpredictable or loosely structured, David has frequent tantrums. On days when any kind of "surprise" occurs (e.g., an anticipated trip to the park is canceled when it storms), David is inconsolable.

- Potential solution: David's parents introduce a "surprise" card on his schedule during weekdays. Initially, they make sure the surprise is something that David enjoys, such as time on the computer. Later, these good surprises are intermixed with surprise activities that David feels neutral about. Finally, his parents intersperse some surprises concerning things that David does not enjoy. Then his parents begin to use a visual schedule and the surprise card for weekends as well.

A visual schedule contains information about activities and their sequence. It is difficult to assure that the plan for the day will remain intact-life happens. Children should be encouraged to cope with the normal variations that occur by introducing choice (i.e., "Do you want to read or do math work first?") or even the surprise lesson taught to David.

\section{Transitions}

Everyone must deal with transitions - between locations, activities, and from person to person. The use of a schedule can help a child cope with what is going to happen at different times of the day. However, some children respond to transitions as if their lives were being turned upside down! Although improving information about the upcoming event may reduce the magnitude of the ensuing tantrum, providing more information (even visually based) is not always sufficient. Some transitions involve changes from activities that are highly rewarding to those that are less rewarding - and no one looks forward to leaving pleasant activities. Some children become upset even when they are asked to change from a less rewarding activity to one that is more rewarding. This reaction may be because the transition involves both leaving something behind and changing to a new activity. Many children respond better when provided with information about the next reward rather than information about the next activity. When the next activity is not inherently rewarding, then adding a separate reinforcer may be necessary.

- Problem: MaryJane has just finished her breakfast and is coloring on a sheet of paper in the kitchen. Her mother tells her that it is time to play in the family room. MaryJane throws the crayons on the floor and screams while her mother physically guides her to the family room. Within a few minutes, MaryJane is calm once more and contentedly playing with her toys. Then her mother tells her that it is time to water the plants-something that MaryJane usually enjoys. MaryJane screams and throws the toys around while her mother coaxes her to get the watering can. This pattern cycles many times each day.

- Potential solution: MaryJane's mother shows MaryJane what her reward will be for making a transition before asking her to change activities. For example, while MaryJane is coloring, her mother brings her one of her favorite toys from the family room. She shows the toy to her daughter, who immediately reaches for it. Then her mother says, "Let's play with the toys in the family room . . . but first we need to put away the crayons." MaryJane puts away the crayons and runs to play with the toy. Later, while MaryJane is still playing with the toy, her mother shows her a picture of the watering can. While she is looking at the picture, her mother says, "Let's go water the plants . . . but first we need to clean up the toys." Throughout the day, MaryJane's mother shows her the next available reward before indicating that MaryJane needs to stop what she is currently doing.

Whereas adults often consider transitioning from activity to activity, most children appear focused on the current reward. This transition strategy aims to provide functional information about the next reward before signaling to the child the removal of the current reward.

\section{Conclusion}

It is extremely important to teach children to continue to use and expand their repertoires of functional communication skills. We have noted several key skills and the strategies to promote them. When these critical skills are weak or missing, behavior problems are often seen in their place. Because all families are unique, it is crucial that each child's communication skills are assessed in his or her home environment, and then a plan to help improve each of the critical skills described in this article can be mapped out. Communication is something that should be worked on during all activities - we do not suggest having a special time to practice communication. 
If someone were to say, "It's 10:00 a.m.-we need to do a PECS lesson!" that would most likely lead to something arbitrary and nonfunctional. Instead, look for opportunities to work on these skills throughout the day and across all activities.

Author Note Andy Bondy, Pyramid Educational Consultants, Inc.; Catherine Horton, Pyramid Educational Consultants, Inc.; Lori Frost, Pyramid Educational Consultants, Inc.

\section{Appendix}

Table 2 Critical Functional Communication Skills Checklist

\begin{tabular}{|c|c|c|}
\hline Skill & Example & Appropriate? \\
\hline \multicolumn{3}{|l|}{ 1. Request reinforcers } \\
\hline \multicolumn{3}{|l|}{ Edibles } \\
\hline \multicolumn{3}{|l|}{ Toys } \\
\hline \multicolumn{3}{|l|}{ Activities } \\
\hline \multicolumn{3}{|l|}{ 2. Request help/assistance } \\
\hline \multicolumn{3}{|l|}{ 3. Request break } \\
\hline \multicolumn{3}{|l|}{ 4. Reject } \\
\hline \multicolumn{3}{|l|}{ 5. Affirm/accept } \\
\hline \multicolumn{3}{|l|}{ 6. Respond to "wait" } \\
\hline \multicolumn{3}{|l|}{ 7. Transition between activities } \\
\hline \multicolumn{3}{|l|}{ 8. Respond to directions } \\
\hline \multicolumn{3}{|l|}{ Visual directions } \\
\hline \multicolumn{3}{|l|}{ Orient to name being signaled. } \\
\hline \multicolumn{3}{|l|}{ "Come here." } \\
\hline \multicolumn{3}{|l|}{ "Stop." } \\
\hline \multicolumn{3}{|l|}{ "Sit down." } \\
\hline \multicolumn{3}{|l|}{ "Give it to me." } \\
\hline \multicolumn{3}{|l|}{ "Go get [familiar item]." } \\
\hline \multicolumn{3}{|l|}{ "Go to [familiar location]." } \\
\hline \multicolumn{3}{|l|}{ "Put it back/down." } \\
\hline \multicolumn{3}{|l|}{ "Let's go." / "Come with me." } \\
\hline \multicolumn{3}{|l|}{ Oral directions } \\
\hline \multicolumn{3}{|l|}{ Orient to name being called. } \\
\hline \multicolumn{3}{|l|}{ "Come here." } \\
\hline \multicolumn{3}{|l|}{ "Stop." } \\
\hline \multicolumn{3}{|l|}{ "Sit down." } \\
\hline \multicolumn{3}{|l|}{ "Give it to me." } \\
\hline \multicolumn{3}{|l|}{ "Go get [familiar item]." } \\
\hline \multicolumn{3}{|l|}{ "Go to [familiar location]." } \\
\hline \multicolumn{3}{|l|}{ "Put it back/down." } \\
\hline \multicolumn{3}{|l|}{ "Let’s go." / "Come with me." } \\
\hline 9. Follow visual schedule & & \\
\hline
\end{tabular}

Note. (C) 2009 Pyramid Educational Consultants.

\section{Reference}

Behavior Analyst Certification Board. (2014). Professional and ethical compliance code for behavior analysts. Littleton, CO: Author.

Publisher's Note Springer Nature remains neutral with regard to jurisdictional claims in published maps and institutional affiliations. 